\title{
Control of recent community-based outbreaks of invasive meningococcal disease in men who have sex with men in Europe and the United States
}

D Weiss (Dweiss@health.nyc.gov) ${ }^{1}, \mathrm{~J}$ K Varma ${ }^{1}$

1. New York City Department of Health and Mental Hygiene, New York, United States

Citation style for this article:

Weiss D, Varma JK. Control of recent community-based outbreaks of invasive meningococcal disease in men who have sex with men in Europe and the United States. Euro Surveill. 2013;18(28):pii=20522. Available online: http://www.eurosurveillance.org/ViewArticle.aspx?Articleld=20522

Article submitted on 10 July 2013 / published on 11 July 2013

Invasive meningococcal disease (IMD) is an infrequent yet deadly infection that constitutes a public health emergency. Control requires rapid identification and diagnosis of suspect cases, prompt administration of antibiotic prophylaxis to close contacts, and recognition of epidemiological links among cases. In 2011, the incidence rate of IMD was 0.73 per 100,000 in European Union (EU) countries, as reported by Marcus et al. in their report on a recent cluster of serogroup C Neisseria meningitidis (MenC) in MSM in this edition of Eurosurveillance [1], in the United States (US), it was 0.25 per 100,000 (an all-time low). While outbreaks of IMD in the US and EU are rare, they can be difficult to control, particularly when the primary risk factor is membership in a social network rather than an organisation or institution [2]. In September 2012, a slowly evolving outbreak of IMD was recognised among men who have sex with men (MSM) in New York City (NYC). The NYC Department of Health and Mental Hygiene (DOHMH), in collaboration with community providers, implemented a meningococcal vaccine campaign to prevent further illness and death [3]. IMD cases in MSM have recently also been recognised in Germany, France, and Belgium. In response to these clusters the European Centre for Disease Prevention and Control, with input from leading experts, composed and distributed a rapid risk assessment to help guide medical and public health authorities [4]. The report by Marcus et al. in this issue summarises the German cluster and highlights important issues regarding local and international IMD control [1].

The first reported outbreak of IMD in MSM occurred in Toronto in 2001 [5]. Subsequently, IMD outbreaks in the MSM community have occurred in Chicago in 2003 [6] and NYC in 2012 and 2013 [3]. All three outbreaks were determined to have been caused by MenC, multilocus sequence typing (MLST) sequence type 11 (ST-11), a common invasive strain of Neisseria meningitidis, and prompted public health officials to offer vaccination to people at risk. The IMD strain responsible for the cases in Germany also belongs to the MenC, ST-11 clonal complex, but direct comparisons to the Canadian and
US strains have not yet been completed. No links to international travel have been identified between the European and US cases.

Although sexual partners are often elicited during IMD contact investigations, sexual orientation had not previously been incorporated into standardised questionnaires in the US or Europe. MSM may be at higher risk of IMD due to an increased frequency of known risk factors, such as bar patronage and smoking [7-9] or through previously unrecognised risk behaviours. Smoking behaviour in NYC among MSM aged 18 to 64 years, however, was not significantly different than among men who have sex only with women (for the years 2009-11: $24 \%$ versus $21 \%, p=0.4$ ) [10]. While bar patronage was reported by Marcus et al. in the German cluster, only one of 17 recent MSM cases in NYC reported that they used bars to meet sexual partners. Drug use has appeared infrequently in the literature, but was reported by half of the MSM outbreak cases since 2012 in NYC (crystal methamphetamine, marijuana, cocaine). Whether these factors act through the sharing of cigarettes or drug paraphernalia, direct mucosal damage facilitating bacterial invasion, or via alteration of immune function is not currently known.

The relatively infrequent identification of this particular MenC strain in non-MSM is likely to represent circulation limited to the MSM social network. However, a unique mechanism of transmission or a susceptibility specific to MSM is possible. In the period August 2010 through June 2013 , for those cases for whom pulsedfield gel electrophoresis was performed, only two of 16 MenC strain matches to the outbreak strain were not MSM, whereas only one of 15 cases in MSM was due an unrelated MenC strain. NYC is conducting a case-control study of IMD in MSM and performing full genome sequencing of MenC isolates from the past decade to better answer these questions.

The US Centers for Disease Control and Prevention (US CDC) and the German Standing Committee on Vaccination recommend using vaccine to control IMD 
Invasive meningococcal disease among men who have sex with men and estimated vaccine doses, New York City, January 2012-June 2013

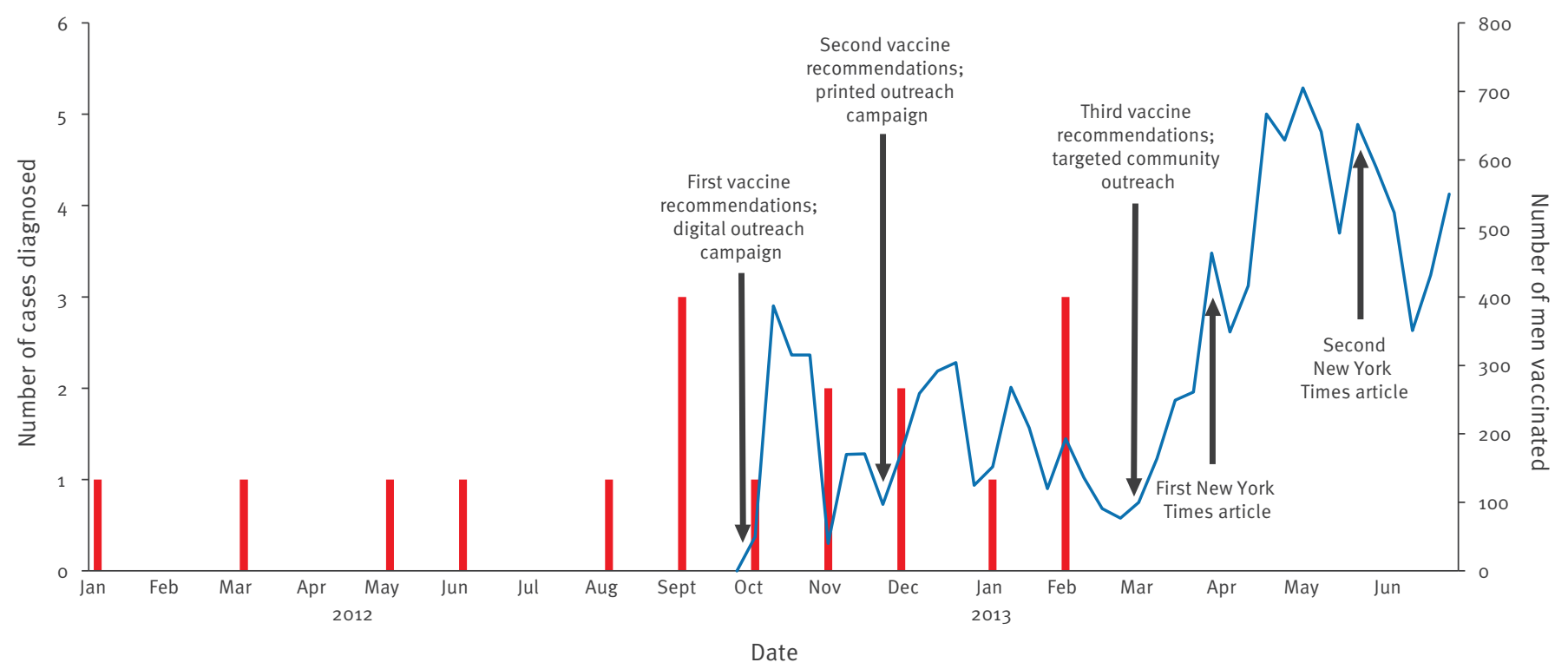

Shown are the number of individuals receiving the first dose of meningococcal vaccine. Numbers include only those public and private vaccine providers who agreed to provide weekly dose administration data and reporting is likely to be incomplete.

outbreaks when the attack rate exceeds a threshold suggestive of ongoing transmission [11-13]. While this recommendation can be readily applied to institutional outbreaks in which the population at risk is easily defined, it is much more difficult to apply to outbreaks in which the only common link is a social network or risk behaviours. In 2005 and 2006, an outbreak of IMD MenC, ST-11, occurred among recovering and current drug users and their close contacts in NYC [14]. The outbreak extended over many months without meeting strict US CDC criteria. The DOHMH responded by administering vaccine to 2,700 persons in affected neighbourhoods, utilising locations such as needle exchange sites, methadone clinics, and drug treatment centres [14].

There are many challenges to controlling IMD outbreaks. Contact tracing and antibiotic prophylaxis are the mainstays of public health practice for individual IMD cases. Cases are often unwilling or unable, however, to disclose sexual and drug using contacts. In NYC we have met with good success through the use of serial patient and family interviews and by utilising staff with experience in obtaining sensitive personal information. Vaccination is an attractive option for MenC IMD clusters; however, identifying the population at risk is challenging in community outbreaks. Vaccine campaigns consume substantial human and financial resources and at this time there is no evidence that a single dose of the vaccines available in the US confers either herd or long lasting immunity (personnel communication: Amanda Cohn, US CDC, October 2011). The current NYC vaccine campaign has cost over 1 million US dollars and has not yet ended. Narrowing the vaccine recommendations to target individuals at highest risk must be balanced against the difficulties of reaching cloistered populations and assuring adequate vaccine access for the under-insured.

A common link among MSM IMD cases in NYC has been use of the Internet and smartphone applications to meet sexual partners. The use of social media has recently emerged as a new method for communicating with individuals potentially exposed to an IMD case [15]. The DOHMH used email messages and mobile phone and online advertisements to advise the MSM community about the outbreak and need for vaccination. Interestingly, conventional media (major newspapers, network television) coverage sparked the largest uptakes in vaccine administration (Figure 1). In the Toronto and Chicago MSM outbreaks $[5,6]$, vaccination campaigns coincided with the apparent cessation of IMD cases in the affected communities (Figures 1 and 2). We do not have definitive evidence that the vaccine campaigns halted these outbreaks. Nevertheless, it is plausible that vaccination campaigns reduce illness and death when focused on persons at highest risk. Defining that risk when the outbreak is occurring in social networks remains an important challenge for public health officials. Of note, France has issued vaccine recommendations for its MSM community based 
Epidemic curve of invasive meningococcal disease cases among current and former drug users and their close contacts, New York City, 2005-06 ( $\mathrm{n}=24)$

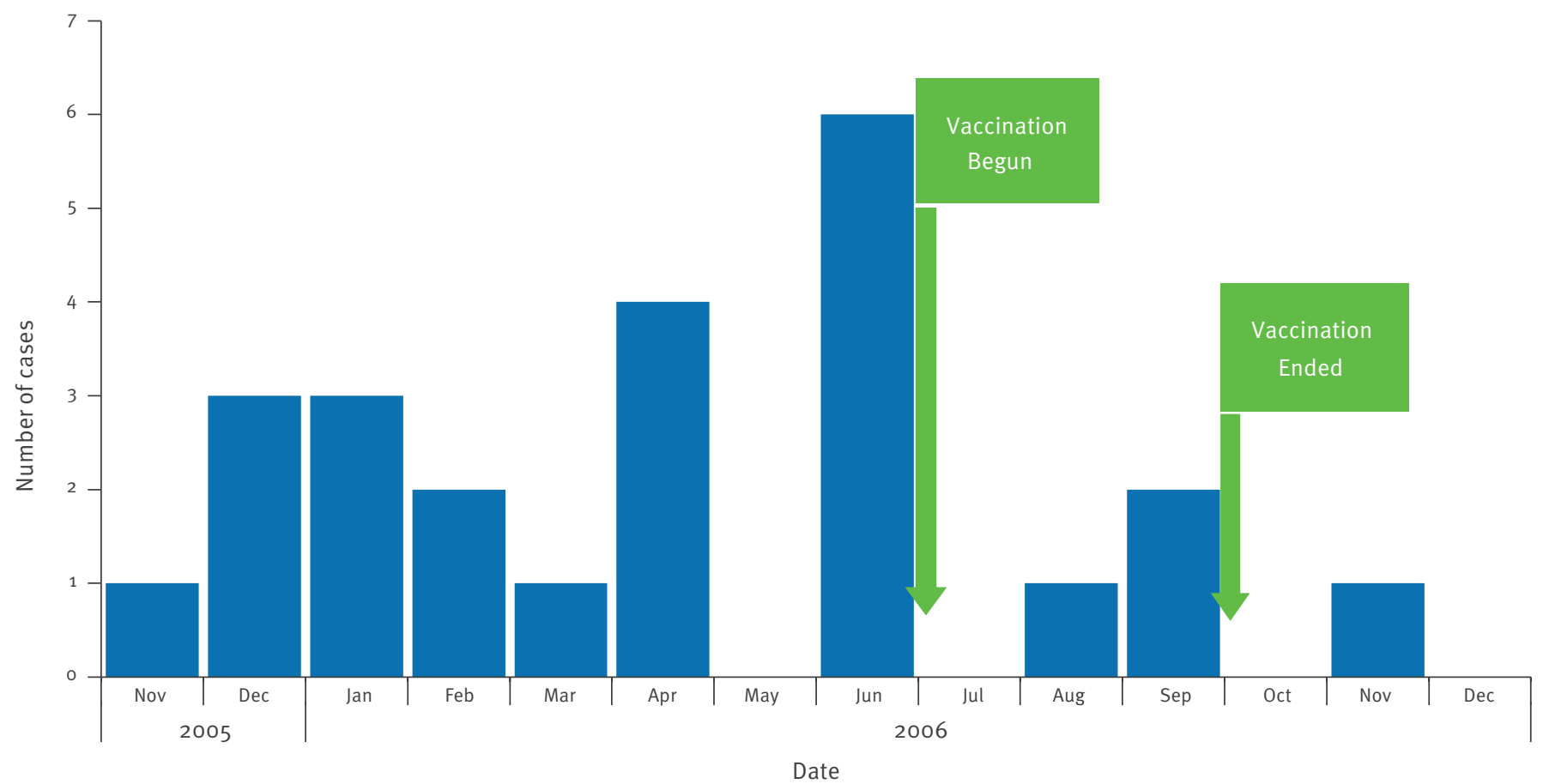

on the recent European clusters [16], and this is under consideration in Germany [1].

IMD outbreaks among MSM communities in North America and Europe over the past 13 years highlight the common problems faced by public health officials. While the spread of IMD from the NYC MSM community to MSM communities in Europe has not been proven, the timing of cases is suspicious and emphasises the borderless nature of infectious diseases in the 21st century. International spread of IMD is not a new phenomenon [17]. After the Hajj pilgrimage in 2000, a serogroup W135 strain resulted in IMD cases in 16 countries [18]. The recent cases among MSM on both sides of the Atlantic emphasise the need for constant vigilance in the assessment of risk groups for IMD, and compel public health agencies to add questions about drug use and sexual practices to their routine investigations.

There is also a need to establish relationships and protocols for the sharing of epidemiologic data and microbiological specimens across continents and oceans, as exists for food-borne pathogens [19]. In light of the potential for similar outbreaks, routine vaccination of MSM, as well as persons infected with human immunodeficiency virus (HIV), have become important policy questions [20]. We are working to determine the costeffectiveness of such a policy and as more is understood about the transmission and behavioural risk factors, how vaccination can be optimised to decrease the morbidity and mortality associated with IMD.
Clinicians should keep IMD in their differential diagnosis when evaluating febrile MSM and public health officials are encouraged to inquire about the sexual partners and social networks of reported IMD cases. 


\section{References}

1. Marcus U, Vogel U, Schubert A, Claus H, BaetzingFeigenbaum J, Hellenbrand W, Wichmann O. A cluster of invasive meningococcal disease in young men who have sex with men in Berlin, October 2012 to May 2013. Euro Surveill. 2013;18(28): $\mathrm{pii}=20523$. Available from: http://www. eurosurveillance.org/ViewArticle.aspx?Articleld=20523

2. Brooks R, Woods CW, Benjamin DK, Rosenstein NE. Increased Case-Fatality Rate Associated with Outbreaks of Neisseria meningitidis Infection, Compared with Sporadic Meningococcal Disease, in the Untied States, 1994-2002. Clin Infect Dis. 2006;43(1):49-54

http://dx.doi.org/10.1086/504804. PMid:16758417.

3. Centers for Disease Control and Prevention (CDC). Notes from the field: serogroup $C$ invasive meningococcal disease among men who have sex with men - New York City, 2010-2012. MMWR Morb Mortal Wkly Rep. 2013;61(51-42):1048.

4. European Centre for Disease Prevention and Control (ECDC). Invasive meningococcal disease among men who have sex with men. Rapid risk assessment. Stockholm: ECDC; 3 July 2013. Available from: http://ecdc.europa.eu/en/publications/ Publications/rapid-risk-assessment-invasive-meningococcaldisease-among-MSM.pdf

5. Tsang RS, Kiefer L, Law DK, Stoltz J, Shahin R, Brown S, et al. Outbreak of serogroup $C$ meningococcal disease caused by a variant of Neisseria meningitidis serotype $2 \mathrm{a}$ ET-15 in a community of men who have sex with men. J Clin Microbiol. 2003;41(9):4411-4. http://dx.doi.org/10.1128/JCM.41.9.44114414.2003. PMid:12958279. PMCid:PMC193786.

6. Schmink S, Watson JT, Coulson GB, Jones RC, Diaz, PS, Mayer LM, et al. Molecular Epidemiologry of Neisseria menigitidis Isolates from an Outbreak of Meningococcal Disease among Men Who Have Sex With Men, Chicago Illinois, 2003. J Clin Microbiol. 2007;45(11): 3768-70. http://dx.doi.org/10.1128/ JCM.01190-07. PMid:17728467. PMCid:PMC 2168499.

7. Cookson ST, Corrales JL, Lotero JO, Regueira M, Binsztein $\mathrm{N}$, Reeves MW, et al. Disco fever: epidemic meningococcal disease in northeastern Argentina associated with disco patronage. J Infect Dis. 1998;178(1):266-9. http://dx.doi. org/10.1086/517450. PMid:9652452.

8. Imrey PB, Jackson LA, Ludwinski PH, England AC 3rd, Fella GA, Fox $B C$, et al. Outbreak of serogroup $C$ meningococcal disease associated with campus bar patronage. Am J Epidemiol. 1996;143(6):624-30. http://dx.doi.org/10.1093/oxfordjournals. aje.a008792 PMid:8610679.

9. Fischer M, Hedberg K, Cardosi P, Plikaytis BD, Hoesly FC, Steingart KR,et al. Tobacco smoke as a risk factor for meningococcal disease. Pediatr Infect Dis J. 1997;16(10):97983. http://dx.doi.org/10.1097/00006454-199710000-00015. PMid:9380476.

10. New York City Department of Health and Mental Hygiene (DOHMH). Community Health Survey 2009-2011 combined. Custom data analysis by Bureau of Epidemiology Services, New York: DOHMH; 5 July 2013.

11. Control and prevention of serogroup $C$ meningococcal disease: evaluation and management of suspected outbreaks: recommendations of the Advisory Committee on Immunization Practices (ACIP). MMWR Recomm Rep. 1997;46(RR-5):13-21. PMid:9048847

12. Cohn AC, MacNeil JR, Clark TA, Ortega-Sanchez IR, Briere EZ, Meissner HC, et al. Prevention and control of meningococcal disease: recommendations of the Advisory Committee on Immunization Practices (ACIP). MMWR Recomm Rep. 2013;62(RR-2):1-28. PMid:23515099.

13. German Standing Committee on Vaccination. Empfehlungen der Ständigen Impfkommission (STIKO) am Robert Koch-Institut. [Recommendations of the Standing Committee on Vaccination (STIKO) at the Robert Koch Institute]. Epidemiol Bull. 2012;30:283-310. German. Available from: http://www.rki.de/ EN/Content/Prevention/Vaccination/recommandations/STIKO Recommendations_2012_en.pdf?__blob=publicationFile)

14. Weiss D, Stern E, Zimmerman C, Bregman B, Yeung A, Das D, et al. Epidemiologic investigation and targeted vaccination initiative in response to an outbreak of meningococcal disease among illicit drug users in Brooklyn, New York. Clin Infect Dis. 2009;48(7):894-901 http://dx.doi.org/10.1086/597257. PMid:19231975.

15. Gounder P, DelRosso P, Adelson S, Rivera C, Middleton $\mathrm{K}$, Weiss D. Using the Internet to trace Contacts of a Fatal Meningococcemia Case-New York City, 2010. J Public Health Manag Pract. 2012;18(4):379-81. PMid:22635194.

16. Haut Conseil de la Santé Publique. Avis relatif au recommandations de vaccination contre le méningocoque $C$, notamment chez les hommes ayant des relations sexuelles avec d'autres hommes. [Opinion on the recommendations for vaccination against meningococcus $C$, particularly among men who have sex with men. Paris: Haut Conseil de la Santé Publique; 3 Jul 2013. Available from: http://www.hcsp.fr/ Explore.cgi/avisrapportsdomaine?clefr $=356$

17. Memish ZA. Meningococcal Disease and Travel. Clin Infect Dis. 2002;34(1):84-90. http://dx.doi.org/10.1086/323403. PMid:11731951.

18. Mayer L, Reeves M, Al-Hamdan N, Sacchi CT, Taha MK, Ajello GW, et al. Outbreak of W135 meningococcal disease in 2000: not emergence of a new W135 strain but clonal expansion within electrophoretic type-37 complex. J Infect Dis. 2002;185(11):1596-605. http://dx.doi.org/10.1086/340414. PMid:12023765.

19. Swaminathan B, Gerner-Smidt P, Ng LK, Lukinmaa S, Kam KM, Rolando S, et al. Building PulseNet International: an interconnected system of laboratory networks to facilitate timely public health recognition and response to foodborne disease outbreaks and emerging foodborne diseases. Foodborne Pathog Dis. 2006. Spring;3(1):36-50.

20. Simon MS, Weiss D, Gulick RM. Invasive Meningococcal Disease in Men Who Have Sex With Men. Ann Intern Med. 2013 June 17.

http://dx.doi.org/10.7326/0003-4819-159-4-201308200-00674 PMid:23778867 